\title{
Does Tobacco Consumption Affect Allocation of Household Expenditure: A Study Literature
}

\author{
Urmatul Uska Akbar ${ }^{1}$, Yollit Permata Sari2* ${ }^{2 *}$ Joan Marta ${ }^{3}$, Doni Satria ${ }^{4}$, Melti Roza \\ Adry $^{5}$, Dewi Zaini Putri ${ }^{6}$, Isra Yeni ${ }^{7}$ \\ 1, 2, 3, 4, 5, 6,7 Universitas Negeri Padang, Padang, Indonesia \\ ${ }^{*}$ Corresponding author. Email: yollitpermata@ gmail.com
}

\begin{abstract}
Tobacco consumption is a continuing social problem around the world. This is because tobacco is a silent killer that contributes to mortality and chronic disease. Even though the consumption of tobacco contributes to social and health problems, it also contributes to economic problems. This is due to smoking is always associated with poverty and one of factors contributed to poverty in developed or developing countries. This research is a literature review study that collects and compares various previous research results related to the impact of the increase in cigarette prices, which is a government policy in reducing cigarette consumption by increasing taxes and customs affecting household consumption of other expenditures such as education, healthcare, communication, fuel and food. In addition, it also identifies whether the costs of cigarette consumption are the same for low-income and high-income households. A review of the literature shows that that the increasing tobacco consumption by poor households will sacrifice their consumption for almost all types of expenditure such as food, education, health, entertainment, communication, and durable goods. The case will different for poor and higher income household. Higher income household will not have affected their consumption on other household expenses as much as poorer income household.
\end{abstract}

Keywords: Tobacco expenditure, Crowding out, Household expenses.

\section{INTRODUCTION}

Tobacco consumption is a continuing social problem around the world. This is because tobacco is a silent killer that contributes to mortality and chronic disease. Even though the consumption of tobacco contributes to social and health problems, it also contributes to economic problems. This is due to smoking is always associated with poverty and one of factors contributed to poverty in developed or developing countries.

WHO records many policies and regulations on limiting cigarette consumption have been enacted? However, the government faces a dilemma or trade off. This is because the existence of cigarette companies is a source of job opportunities and income for the government (WHO: 2006). So, although it has an impact on poverty, tobacco consumption also has an impact on the economy [1]. [2] estimates that about 250,000 Indonesians have died from smoking-related illnesses. However, the tobacco industry also recruits around 16.4 million people every year. The lift indicates that those recruited outnumber those who have died.
The Southeast Asia Tobacco Control Alliance states that Indonesia is one of the countries that should receive special attention from the world towards tobacco consumption cases. In Indonesia, sales of tobacco always increase every year. In addition, the number of smokers in Indonesia is also the highest among ASEAN countries.

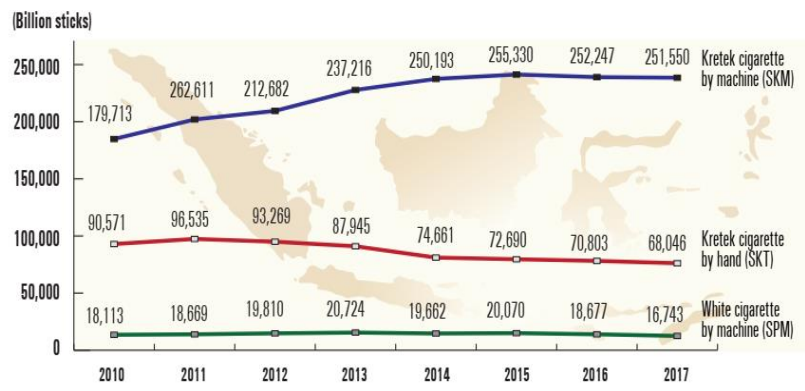

Source: Southeast Asia Tobacco Control Alliance

Figure 1 Cigarette Production in Indonesia 
Table 1. Point of Sale of Cigarette in ASEAN

\begin{tabular}{|l|c|c|c|}
\hline \multicolumn{1}{|c|}{ Country } & Total Smokers & Cigarette Retailers & Cigarette retailer per 10,000 smoker \\
\hline Indonesia & $65,188,338$ & $2,500,000$ & 383 \\
\hline Malaysia & $4,991,458$ & 80,000 & 160 \\
\hline Philippines & $16,500,000$ & 694,821 & 421 \\
\hline Singapore & 345,000 & 4,617 & 134 \\
\hline Thailand & $10,676,361$ & 870,000 & 815 \\
\hline Vietnam & $15,600,000$ & $303,333,333$ & 194 \\
\hline
\end{tabular}

Sources: Health Outcome in Human Development Report

Smoking is like a chronic disease that affects children, adolescent and elderly. [3] found that there is a direct relationship between people who started smoking in childhood and continued smoking in adulthood. The smoking habit is not only dominated by elderly, but also adolescent. This is because adolescents who initially tried smoking out of curiosity and had smoked for more than a month tended to continue smoking into adulthood despite the efforts that they made for quitting this habit, while those who never started smoking during adolescence were less likely to become smokers when they were adult [4]. This is due to smoking makes children and adults to become addicted so that it is difficult to quit [5].

The environment factor, looking at fellow smoking, stress in facing schoolwork and work are factors that cause people to decide to smoke.[6] said that young smokers having friends who are smokers also make them to be smokers so that the presence of parents is an important factor in preventing smoking habit from increasing among children and adolescent. Another interesting factor contributed for smoking habit is that advertisements and promotions on television [7]. In addition, [8] also found that the product differentiations of cigarettes also encourage the curiosity of young people to consume cigarettes, such as electronic cigarettes.

Significant progress has been made for tobacco consumption control in many countries. WHO stated that the regulation about price and imposition of taxes is one of the effective ways to reduce tobacco consumption. The ASEAN tobacco control report noted that every $10 \%$ increase in cigarette prices will reduce teenage smoking by about $7 \%$ and overall cigarette consumption by about $4 \%$. In addition, the increase in taxes also has a good impact on increasing the revenue of government.

Tobacco users respond differently to an increase in price of cigarette. Some of them reduce the consumption for tobacco. However, some of them reduce their consumption of other expenses such as education, health, fuel, entertainment and expenditure on food. Wang found that spending on tobacco causes households to sacrifice spending on education and health [9]. Meanwhile, [10] found that cigarette consumption causes rural and urban communities to be unable to allocate their expenses for education and clothing.

\section{METHOD}

Therefore, this study focuses on comparing literature studies about how the allocation of expense for tobacco consumers and non-tobacco consumers, at the extent to which household spending on tobacco consumption can reduce other household and identifying the impact of increased household spending on tobacco on other types of expenditure, whether the increase in tobacco expenditure causes other expenses to decline or vice versa, and then compare it in rural and urban areas, or developed countries and developing countries.

This research is a literature review study that collects and compares various previous research results related to the impact of the increase in cigarette prices, which is a government policy in reducing cigarette consumption by increasing taxes and customs affecting household consumption of other expenditures such as education, healthcare, communication, fuel and food. In addition, it also identifies whether the costs of cigarette consumption are the same for low-income and highincome households.

The type of research used is descriptive and exploratory analysis. Descriptive analysis aims to describe the relationship between the variables which being analyzed in this study. This exploratory research aims to explain the description of the phenomenon from various research sources regarding the crowding out analysis of tobacco consumption to the allocation of household expenditure consumption to other types of expenditure. This research method uses qualitative and quantitative data collection techniques derived from literature reviews. The data of this study were obtained from previous research related to total household expenditure on cigarettes, total household expenditure on other consumption such as education, health, entertainment and fuel, and data on types, which expenses are sacrificed when household expenditure on cigarettes increases. Furthermore, this study will reveal the pros and cons of each of the previous studies examined regarding whether cigarette consumption affects expenditure on other types of consumption expenditure. 


\section{RESULTS AND DISCUSSION}

Consuming tobacco has an adverse effect on health [11]. Tobacco is fast becoming one of the leading causes of death worldwide [12]. However, cigarettes become part of the social habits of many people. So that cigarettes are a commodity that is widely traded and give benefits for many people. Several recent studies have been documented about crowding out of tobacco consumption toward household expenditures show many people actually face money gone up in Smoke, so they have to choose whether to allocate their money towards tobacco consumption or fulfil nutrition. It ends up by sacrificing nutrition to meet their cigarette consumption. It makes poorer households are at greater risk of being malnourished, and spending their limited household income on tobacco, not on food or basic necessities [13].

The head of households who smoke also spend less money on fresh food such as fruit and vegetables than non-smoking households and that difference increases after the tax increase causes cigarette prices to increase. Poor smoking households are experiencing significant changes. So there is a crowding out effect on the expenditure of fresh food for households who smoke, with a much larger effect for households in the poorest group in which they allocate more money for cigarette [14].

Tobacco consumption also causes households to switch from income to food rather than spending on non-food items. In addition, tobacco consumption also causes the quantity and quality of food consumed by poor households to decrease, so that it also affects the nutrition of these households, and in the end also affects malnutrition for their children[11]. Tobacco consumption will significantly increase when household income also increases. So that the increase in the price of tobacco products will cause a decrease in the number of cigarettes smoked. Households that have health insurance will reduce cigarette consumption so they will tend to refrain from smoking [15].

Apart from spending on food, household smokers will also sacrifice others expenses for other consumption. By estimating the expenditure system of consumer demand for cigarettes, food, alcohol, housing, clothing, transportation, health. Descriptive data show that, smokers spend less on housing expenses compared to non-smokers, In addition, cigarette consumption also shows that as cigarette prices increase, households increase their expenditure on food and reduce their expenditure on clothing [16].

[17] found that spending on clothing, housing, education, energy, transport and communication was the type of expenditure that smokers allocated less than non-tobacco user households. In addition, he also found that the share of expenditure on food and health of tobacco user households was greater than that of nontobacco user households. The crowding out analysis found that households who consume tobacco reduce their consumption of clothing, housing, education, energy, and transportation and communication.

Previous empirical studies have used the AIDS equation system or the Almost Ideal Demand System in which the budget portion of various commodities is linearly related to the logarithm of total real expenditure and the logarithm of relative values. Nonparametric analysis of consumer spending patterns shows that the Engel curve requires squared terms in the expenditure logarithm. While popular demand models such as the Trans log or Almost Ideal Demand System allow flexible price responses in a theoretically coherent structure, they have a linear Engel curve expenditure share in the logarithm of total expenditure. So that the Quadratic Almost Ideal Demand System is needed [18].

By using the AIDS equations, Surjono found that smoking is normal goods., When the household income of smokers increases, consumption of cigarettes also increases. Meanwhile, demand for cigarettes is inelastic for poor households. This means that the increase in cigarette prices will not cause the amount of cigarette consumption to decrease as much as the price increase. When there was an increase in cigarette prices, cigarette consumption among poor households decreased by 0.4204 percent in 2008, 0.7040 in 2009, and 0.7799 in 2010. When the crowding out analysis was carried out, in 2008, there was an increase the price of cigarettes will cause households to sacrifice spending on almost all food commodities. In the following year, the commodities sacrificed were fish, shrimp, squid, meat, eggs, milk, while in 2010, poor households sacrificing expenses for all foodstuff commodities.

Using the Quadratic Almost Ideal System [19] found that in general cigarette consumption by smokers will sacrifice consumption for food but not as much as non-food expenditure. Expenditures on tobacco cause consumers to sacrifice more consumption for durables followed by food grains, health and education. [20] found that using a quadratic conditional Engel curves analysis, showed that tobacco consumer households have lower consumption of certain commodities such as milk, education, clean fuels and entertainment which may have a more direct effect on women and children in household. Tobacco was also found to have a negative effect on per capita nutritional intake. The crowding out trait was found to be similar among low- and highincome households

Ioannis Kostakis also found that tobacco consumption causes households to allocate less expenditure on food, clothing, health, durable goods, but does not affect their consumption for communication, education, and spending on hotels and restaurants. These findings are supported by [21], he founds that households who consume tobacco spend less on 
education, communication, food, durable goods, while expenditure on transportation is the type of expenditure that is not sacrificed.

[22] stated that the effect of crowding out was only felt by households with low income. Middle and upper income households will not be affected or will not reduce their consumption of other expenses when cigarette prices increase. He also found that for the poor it will affect other types of expenditure except for food and health. The interesting finding found by [23], From the socio demographic character he found that many smokers do not have a high level of education. Because of the low level of education, they do not realize dangers of consuming tobacco for health. So that an increase in cigarette prices causes it to sacrifice consumption for education.

\section{CONCLUSION}

This study collects and identifies literature empirical study about the crowding out analysis of tobacco consumption on other household expenses. This studies also emphasizes the extent to which tobacco consumption will sacrifice household expenses. The results of many empirical studies found that the increasing tobacco consumption by poor households will sacrifice their consumption for almost all types of expenditure such as food, education, health, entertainment, communication, and durable goods. The case will different for poor and higher income household. Higher income household will not have affected their consumption on other household expenses as much as poorer income household.

\section{REFERENCES}

[1] V. U. Ekpu and A. K. Brown, "The Economic Impact of Smoking and of Reducing Smoking Prevalence : Review of Evidence," pp. 1-35, 2015, doi: 10.4137/TUI.S15628.RECEIVED.

[2] T. Lian and U. Dorotheo, The Tobacco Control Atlas: ASEAN Region, Fourth Edition, no. September. 2019.

[3] G. M. M. de Oliveira et al., "2019 Recommendations for reducing tobacco consumption in the Portuguese-speaking countries," Rev. Port. Cardiol. (English Ed., vol. 38, no. 4, pp. 233-244, 2019, doi: 10.1016/j.repce.2019.05.011.

[4] M. Yuan, S. J. Cross, S. E. Loughlin, and F. M. Leslie, "Nicotine and the adolescent brain," $J$. Physiol., vol. 593, no. 16, pp. 3397-3412, 2015, doi: 10.1113/JP270492.

[5] R. B. Heyman, "Reducing tobacco use among youth," Pediatr. Clin. North Am., vol. 49, no. 2, pp. 377-387, 2002, doi: 10.1016/S00313955(01)00010-4.
[6] N. Bejjani, C. El Bcheraoui, and S. M. Adib, "The social context of tobacco products use among adolescents in Lebanon (MedSPADLebanon)," J. Epidemiol. Glob. Health, vol. 2, no. 1, pp. 15-22, 2012, doi: 10.1016/j.jegh.2012.02.001.

[7] P. Changpetch and D. Haughton, "Associations and determinants of tobacco consumption in Thailand," Kasetsart J. Soc. Sci., vol. 40, no. 1, pp. 213-224, 2019, doi: 10.1016/j.kjss.2017.07.009.

[8] F. Ferretti, "Understanding Tobacco Use in Different Countries," Neurosci. Nicotine, pp. 18, 2019, doi: 10.1016/b978-0-12-8130353.00001-0.

[9] H. Wang, J. L. Sindelar, and S. H. Busch, "The impact of tobacco expenditure on household consumption patterns in rural China," Soc. Sci. Med., vol. 62, no. 6, pp. 1414-1426, 2006, doi: 10.1016/j.socscimed.2005.07.032.

[10] S. John, S. Vaite, D. Efroymson, and S. Fitzgerald, "Tobacco and Poverty: Observations from India and Bangladesh," no. October 2002, pp. 1-72, 2002.

[11] S. Block and P. Webb, "Up in Smoke: Tobacco use, expenditure on food, and child malnutrition in developing countries," Econ. Dev. Cult. Change, vol. 58, no. 1, pp. 1-23, 2009, doi: $10.1086 / 605207$.

[12] S. Bonu, M. Rani, P. Jha, D. H. Peters, and S. N. Nguyen, "Household tobacco and alcohol use, and child health: An exploratory study from India," Health Policy (New. York)., vol. 70, no. 1, pp. 67-83, 2004, doi: 10.1016/j.healthpol.2004.02.003.

[13] M. J. Husain, M. Virk-Baker, M. Parascandola, B. H. Khondker, and I. B. Ahluwalia, "Money Gone Up in Smoke: The Tobacco Use and Malnutrition Nexus in Bangladesh," Ann. Glob. Heal., vol. 82, no. 5, pp. 749-759.e1, 2016, doi: 10.1016/j.aogh.2016.07.005.

[14] H. J. Jin and S. M. Cho, "Effects of cigarette price increase on fresh food expenditures of low-income South Korean households that spend relatively more on cigarettes," Health Policy (New. York)., pp. 1-8, 2020, doi: 10.1016/j.healthpol.2020.08.004.

[15] A. Bilgic, W. J. Florkowski, S. T. Yen, and C. Akbay, "Tobacco spending patterns and their health-related implications in Turkey," J. Policy Model., vol. 35, no. 1, pp. 1-15, 2013, doi: 10.1016/j.jpolmod.2012.09.004.

[16] S. H. Busch, M. Jofre-Bonet, A. T. Falba, and L. 
S. Jody, "Tobacco spending and its crowding out of other goods," Natl. Bur. Econ. Res., no. December, 2004.

[17] M. J. Husain, B. K. Datta, M. K. Virk-Baker, M. Parascandola, and B. H. Khondker, "The crowding-out effect of tobacco expenditure on household spending patterns in Bangladesh," PLoS One, vol. 13, no. 10, pp. 1-15, 2018, doi: 10.1371/journal.pone.0205120.

[18] K. Bruna and Q. Van Tran, "The central banks' ability to control variability of money market interest rates: The case of inflation targeting countries," J. Econ. Behav. Organ., vol. 176, pp. 384-402, 2020, doi: 10.1016/j.jebo.2020.04.012.

[19] J. Jumrani and P. S. Birthal, "Does consumption of tobacco and alcohol affect household food security? Evidence from rural India," Food Secur., vol. 9, no. 2, pp. 255-279, 2017, doi: 10.1007/s12571-017-0660-8.

[20] R. M. John, H. Ross, and E. Blecher, "Tobacco expenditures and its implications for household resource allocation in Cambodia," Tob. Control, vol. 21, no. 3, pp. 341-346, 2012, doi: 10.1136/tc. 2010.042598 .

[21] A. O. Nyagwachi, G. Chelwa, and C. van Walbeek, "The effect of tobacco- and alcoholcontrol policies on household spending patterns in Kenya: An approach using matched difference in differences," Soc. Sci. Med., vol. 256, no. May, 2020, doi: 10.1016/j.socscimed.2020.113029.

[22] C. yun Pu, V. Lan, Y. J. Chou, and C. fu Lan, "The crowding-out effects of tobacco and alcohol where expenditure shares are low: Analyzing expenditure data for Taiwan," Soc. Sci. Med., vol. 66, no. 9, pp. 1979-1989, 2008, doi: 10.1016/j.socscimed.2008.01.007.

[23] R. M. John, “Crowding out effect of tobacco expenditure and its implications on household resource allocation in India," Soc. Sci. Med., vol. 66, no. 6, pp. 1356-1367, 2008, doi: 10.1016/j.socscimed.2007.11.020. 